Prose Fiction of the Cuban Revolution 
THIS PAGE INTENTIONALLY LEFT BLANK 
Latin American Monographs, No. 37 Sponsored by the Institute of Latin American Studies The University of Texas at Austin 
THIS PAGE INTENTIONALLY LEFT BLANK 


\section{Prose Fiction of the Cuban Revolution}

BY SEYMOUR MENTON

UNIVERSITY OF TEXAS PRESS - AUSTIN 
Library of Congress Cataloging in Publication Nata

Menton, Seymour.

Prose fiction of the Cuban revolution.

(Latin American monographs; no. 37)

Bibliography: p.

Includes index.

I. Cuban fiction-2oth century-History and

criticism. 2. Cuba in literature. I. Title.

II. Series: Latin American monographs (Austin, Tex.); no. 37 .

$\mathrm{PQ}_{7382 . \mathrm{M}_{4} \quad 863 \quad 75-5993}$

ISBN $0-292-7642 \mathrm{I}-9$

Copyright (C) 1975 by Seymour Menton

All rights reserved

Printed in the United States of America

ISBN 978-0-292-76383-8 (library e-book)

ISBN 978-0-292-76384-5 (individual e-book) 
... nunca be sido incondicional de nada ni de nadie.

-Ernesto Sábato

... sin libertad de critica y sin pluralidad de opiniones y grupos no bay vida politica. Y para nosotros, hombres modernos, vida política es sinónimo de vida racional y civilizada.

-Octavio Paz

La literatura en general y la novela en particular, son expresión de descontento: el servicio social que prestan consiste, principalmente en recordar a los hombres que el mundo siempre estará mal becho, que la vida siempre deberá cambiar.

- Mario Vargas Llosa 
THIS PAGE INTENTIONALLY LEFT BLANK 